\title{
FREQUENCY OF COMPLIANCE TO GUIDELINE RECOMMENDED TREATMENT IN HEART FAILURE PATIENTS WITH LVEF $<40 \%$
}

\author{
Ammara Avais, Imtiaz Ahmed Khan, Hafiza Sonia Iqbal, Anam Fatima Janjua, Javeria Asghar, Javeria Kamran, \\ Samina Rashid, Erum-Un-Nisa, Naseer Samore, Sohail Aziz
}

Armed Forces Institute of Cardiology/National Institute of Heart Disease (AFIC/NIHD)/National University of Medical Sciences (NUMS) Rawalpindi Pakistan

\begin{abstract}
Objective: To determine the frequency of compliance to guideline recommended treatment among patients with STAGE-C or STAGE-D heart failure and LVEF $<40 \%$.

Study Design: Descriptive cross-sectional study.

Place and Duration of Study: Adult cardiology department of AFIC/NIHD, Rawalpindi, from Sept to Dec 2019. Methodology: Eighty Four patients of Heart Failure with reduced LVEF after satisfying inclusion and exclusion criteria were recruited in this study through non-probability consecutive sampling technique. Data was collected from ER and OPD patients through complete history based on demographics (i.e. age and gender), co-morbidities (i.e. diabetes, hypertension, CAD and smoking history), previous EF record measured on 2D-echo, functional improvement of the patients using NYHA dyspnea class and guideline recommended medication history with compliance. The data was analyzed using SPSS version 23.

Results: A total of 84 patients of Heart Failure with LVEF $=31.61 \pm 7.61 \%$ were enrolled out of whom $62(73.8 \%)$ were male and $22(26.2 \%)$ female patients. The mean age of patients was $62.26 \pm 9.879$ years. About $30(35.7 \%)$ patients were diabetic, 44 (52.4\%) were hypertensive, 19 (22.6\%) were current smokers, 16 (19\%) were ex-smokers and $49(58.2 \%)$ were nonsmokers. Those with history of CAD were (SVCAD=8 (9.5\%), DVCAD=14 (16.7\%), TVCAD $15(17.9 \%)$. Compliance of patients to treatment was $74(88.1 \%)$ good. Patients presenting with NYHA Class I/II $3(3.6 \%) / 20(23.6 \%)$ showed significant improvement after medical therapy 34 (40.5\%)/30 (35.7\%), whereas those with class III/IV did not show significant improvement in functional status.

Conclusion: This survey shows that patient's compliance is relatively goods but patients with NYHA III/IV were receiving suboptimal treatment. Secondly patients presenting with NYHAI/II after medical therapy showed significant improvement in functional status as compared to those with NYHA III/IV. Thereby further actions are needed for improving quality of life and standard of care among HF patients by optimization of treatment according to guidelines.
\end{abstract}

Keywords: Coronary artery disease, Left ventricular ejection fraction, New-York heart association.

This is an Open Access article distributed under the terms of the Creative Commons Attribution License (http://creativecommons.org/licenses/by/4.0), which permits unrestricted use, distribution, and reproduction in any medium, provided the original work is properly cited.

\section{INTRODUCTION}

Chronic heart failure $(\mathrm{CHF})$ is a worldwide weight for human services frameworks. Numerous patients across the world are influenced by this condition, which is related with high death rates and intermittent and delayed hospitalizations ${ }^{1}$. From a physiological point of view, HF can be defined as an inadequate cardiac output to meet metabolic demands or adequate cardiac output secondary to compensatory neurohormonal activation (generally manifesting as increa-

Correspondence: Dr Ammara Avais, Department of Cardiology, AFIC/NIHD Rawalpindi Pakistan sed left ventricular filling pressure) ${ }^{2,3}$. HFrEF is defined as the clinical diagnosis of $\mathrm{HF}$ and $\mathrm{EF}$ $\leq 40 \%$. Those with LV systolic dysfunction commonly have elements of diastolic dysfunction as well ${ }^{8}$. Although coronary artery disease (CAD) with and without myocardial infarction (MI) is a majorcause of $\mathrm{HFrEF}$, many other risk factors may lead to LV enlargement and $\mathrm{HFrEF}^{4}$. Chronic heart failure affects more than 6.5 million Americans, and its prevalence may increase to more than 8 million Americans by 20305. It is a global disease which is affecting a large number of people across the world in those areas where the heart failure risk factors like hypertension, diabe- 
tes and ischemic heart disease is common' ${ }^{6}$. It is very much reported that compliance to medication is an essential piece of the self care for heart failure patients. Regardless, numerous heart failure patients neglect to accept their drugs as endorsed at the danger of adverse health outcomes. Medications planned for improving adherence to heart failure, may help reduce hospital readmissions and mortality ${ }^{6,7}$. The pharmacological treatment for heart failure with reduced ejection fraction is changed in last 25 years. The introduction of angiotensin converting enzyme inhibitors (ACEIs), beta-blockers, angiotensin receptor blockers (ARBs), mineralocorticoid receptor antagonists (MRAs) and, more recently, ivabradine has been associated with a significant outcome improvement in large clinical randomized controlled trials. International guidelines recommend these classes of drugs to improve mortality and/or reduce hospitalizations for heart failure $(\mathrm{HF})$, with the aim of achieving the target doses used in the randomized clinical trials 8,9 .

\section{METHODOLOGY}

This cross sectional study was carried out at Emergency Department and Out Patient Department of Armed Forces Institute of Cardiology and National Institute of Heart Diseases, Rawalpindi, Pakistan from 1st September to 31st December, 2019. Patients satisfying following inclusion criteria were recruited for the study; all outpatients ( $>18$ years old) with $\mathrm{CHF}$ of either gender, patients hospitalized for worsening $\mathrm{HF}$ within the previous 3-15 months and patients with reduced ejection fraction as demonstrated by left ventricular ejection fraction (LVEF) $\leq 40 \%$ measured on the most recent echocardiogram $(\leq 2$ years). Following patients were excluded i.e. Patients in whom revascularization was planned, patients with volvuli pathology, liver pathology or with chronic kidney disease and patients with ejection fraction more than $40 \%$ i.e. heart failure with preserved ejection fraction are excluded from study. In the current participants satisfying theinclusion and exclusion criteria were selected using non-probability consecutive sampling technique. Data of all participants was recorded on a pre- designed preform. Data was collected from ER and OPD patients through complete history based on demographics (i.e. age and gender), comorbidities (i.e. diabetes, hypertension, CAD and smoking history), previous EF record measured on 2D-echo, functional improvement of the patients using NYHA dyspnea class and guide line recommended medication history with compliance. Formal permission was taken from hospital ethical committee. Written informed consent was taken from participants of study. Anonymity and confidentiality of participants' response and clinical data was maintained. Statistical analysis was performed using statistical software SPSS23. Mean and standard deviation was calculated for quantitative variable i.e. age. Frequency and percentage was calculated for qualitative variable i.e. gender, diabetes mellitus, hypertension, smoking history.

\section{RESULTS}

A total of 84 patients of Heart Failure with $\mathrm{LVEF}=31.61 \pm 7.611$ were enrolled out of whom $62(73.8 \%)$ were male and $22(26.2 \%)$ female patients. The mean age of patients was $62.26 \pm$ 9.879 years. About $30(35.7 \%)$ patients were diabetic, 44 (52.4\%) were hypertensive, 19 (22.6\%) were current smokers, 16 (19\%) were ex-smokers and $49(58.2 \%)$ were nonsmokers. Those with

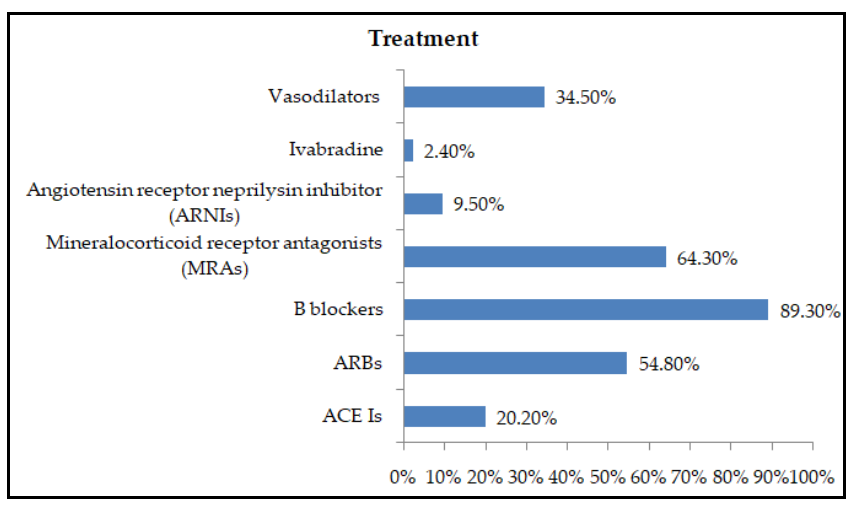

Figure: Type of guideline recommended medications for the treatment of heart failure.

history of CAD were: (SVCAD=8 (9.5\%), DVCAD $=14(16.7 \%)$, TVCAD $15(17.9 \%)$. Compliance of patients to treatment was 74 (88.1\%) good. Patients presenting with NYHA Class I/II, 3 $(3.6 \%) / 20(23.6 \%)$, showed significant improve- 
ment in functional status after medical therapy, $34(40.5 \%) / 30(35.7 \%)$, whereas those with class III/IV, 35 (41.7\%)/ 26 (31.0\%), did not show

Table-I: Characteristics of Study Population $(\mathrm{n}=84 \%)$.

\begin{tabular}{|c|c|c|c|c|}
\hline $\begin{array}{l}\text { S. } \\
\text { No }\end{array}$ & \multicolumn{2}{|c|}{ Variables } & \multicolumn{2}{|c|}{$\begin{array}{c}\text { Mean } \pm \text { SD / } \\
\text { Frequency (Percentage) }\end{array}$} \\
\hline \multirow{2}{*}{1.} & \multicolumn{4}{|l|}{ Age } \\
\hline & \multicolumn{2}{|l|}{ Age } & \multicolumn{2}{|c|}{$62.26 \pm 9.879$ years } \\
\hline \multirow{3}{*}{2.} & \multicolumn{4}{|l|}{ Gender } \\
\hline & \multicolumn{2}{|l|}{ Male } & \multicolumn{2}{|c|}{$62(73.8 \%)$} \\
\hline & \multicolumn{2}{|l|}{ Female } & \multicolumn{2}{|c|}{$22(26.2 \%)$} \\
\hline 3. & \multicolumn{2}{|l|}{ DM } & \multicolumn{2}{|c|}{30 (35.7\%) } \\
\hline 4. & \multicolumn{2}{|c|}{ Hypertension } & \multicolumn{2}{|c|}{$44(52.4 \%)$} \\
\hline \multirow{4}{*}{5.} & \multicolumn{4}{|c|}{ Smoking } \\
\hline & \multicolumn{2}{|c|}{ Current Smoker } & \multicolumn{2}{|c|}{$19(22.6 \%)$} \\
\hline & \multicolumn{2}{|c|}{ Ex-Smoker } & \multicolumn{2}{|c|}{$16(19 \%)$} \\
\hline & \multicolumn{2}{|c|}{ Non-Smoker } & \multicolumn{2}{|c|}{$49(58.2 \%)$} \\
\hline \multirow{4}{*}{6.} & \multicolumn{4}{|l|}{ CAD } \\
\hline & \multicolumn{2}{|l|}{ SVCAD } & \multicolumn{2}{|c|}{$8(9.5 \%)$} \\
\hline & \multicolumn{2}{|c|}{ DVCAD } & \multicolumn{2}{|c|}{$14(16.7 \%)$} \\
\hline & \multicolumn{2}{|c|}{ TVCAD } & \multicolumn{2}{|c|}{$15(17.9 \% \%$} \\
\hline 7. & \multicolumn{2}{|l|}{$\mathrm{EF}(\%)$} & \multicolumn{2}{|c|}{$31.61 \pm 7.611$} \\
\hline \multicolumn{5}{|c|}{ Table-II: NYHA Functional Classes. } \\
\hline NYI & Class & $\begin{array}{r}\text { Be } \\
\text { Trea }\end{array}$ & $\begin{array}{l}\text { re } \\
\text { lent }\end{array}$ & $\begin{array}{c}\text { After } \\
\text { Treatment }\end{array}$ \\
\hline Clas & & $3(3$ & & $34(40.5 \%)$ \\
\hline Clas & & $20(2$ & $6 \%)$ & $30(35.7 \%)$ \\
\hline Clas & & $35(4$ & $7 \%)$ & $14(16.7 \%)$ \\
\hline Clas & & 263 & $0 \%)$ & $6(7.1 \%)$ \\
\hline
\end{tabular}

significant improvement in functional status, $14(16.7 \%) / 6(7.1 \%)$, as assessed by NYHA, as patients with NYHA III/IV were receiving suboptimal treatment.

\section{DISCUSSION}

HF has poor prognosis over the long run and carries an elevated risk of $\mathrm{CV}$ and $\mathrm{HF}$ admission, irrespective of $\mathrm{EF}^{10}$. In the present study aim was to check for compliance of HF patients to GDMT by assessing improvement in functional status by NYHA, in order to reduce the risk of adverse future outcomes. Result showed that compliance was good but patients with NYHAIII/IVwere receiving suboptimal therapy.

The pathway to improve outcomes after HF hospitalization begins with admission, continues through the process of decongestion and transition to oral therapies before the day of discharge, and connects through the first postdischarge follow-up ${ }^{11}$.

Complex associations between co-morbidities themselves as well as between co-morbidities andthe cardiovascular system gave rise to the development of HF (both HFpEF and HFrEF). On the other hand, HF may give rise to co-morbidities, which is associated with adverse outcomes. In present study HTN is the most prevalent risk factor followed by history of smoking, as compared to a study conducted abroad showed that obesity and diabetes were most prevalent risk factors for most of HF related co-morbidities ${ }^{12,13}$.

Although optimal pharmacological treatment for heart failure, with reduced ejection fraction (HFrEF), is carefully scripted by treatment guidelines, many HF patients are not treated with guideline directed medical therapy (GDMT) in clinical practice ${ }^{14,15}$. Similar to this, our study also highlighted that among patients with NYHA III/IV were receiving sub optimal therapy. Sacubitril/valsartan, an angiotensin receptor neprilysin inhibitor (ARNI), is new class of drug with mortality benefit, (PARADIGM-HF) trial, showed about $20 \%$ reduction in cardiovascular death in patients who received it compared with those who received enalapril in the Prospective Comparison of ARNI with ACEI (Angiotensin-Converting Enzyme Inhibitors) ${ }^{16}$.

From The Champ-HF Registry, conducted in US outpatients of HFrEF, the large majority of eligible patients did not receive required dosage, there by further efforts are needed to improve titration of medical therapy according to guideline recommendations ${ }^{17}$.

In our population setting similar efforts are needed for appropriate management of patients for their future well-being.

Similar to our study results, patients with NYHA class I/II on GDMT showed significant improvement in functional status, a study conducted at Imperial College of Science Technology 
and Medicine, London, UK in 2007, which showed that observer variation exist in assessing NYHA class, but HF patients with class II/III gave a relatively better result ${ }^{18}$. Similarly another study showed that NYHA class II patients had a better survival compared with those in NYHA class III-IV19,20.

\section{CONCLUSION}

This survey shows that patient's compliance is relatively goods but patients with NYHA III/ IV were receiving suboptimal treatment. Secondly patients presenting with NYHAI/II after medical therapy showed significant improvement in functional status as compared tothose with NYHA III/IV. Thereby further actions are needed for improving quality of life and standard of care among HF patients by optimization of treatment according to guidelines.

\section{CONFLICT OF INTEREST}

This study has no conflict of interest to be declared by any author.

\section{REFERENCES}

1. Komajda M, Anker SD, Cowie MR. Physicians' adherence to guideline-recommended medications in heart failure with reduced ejection fraction: Data from the Qualify global survey, Eur J Heart Fail 2016; 18(5): 514-22.

2. Hood SR, Giazzon AJ, Seamon G. Association between medication adherence and the outcomes of heart failure. Pharmacotherapy 2018; 38(5): 539-45.

3. Savarese G, Lund LH. Global public health burden of heart failure. Card Fail Rev 2017; 3(1): 7-11.

4. Ruppar TM, Cooper PS, Mehr DR, Delgado JM,. Medication adherence interventions improve heart failure mortality and read mission rates: systematic review and metaanalysis of controlled trials. J Am Heart Assoc 2016; 5(1): 1-4.

5. Jessup M, Abraham WT, Casey DE, Feldman AM, Francis GS, Ganiats TG. Focused update: ACCF/AHA Guidelines for the diagnosis and management of heart failure in adults: a report of the American College of Cardiology Foundation / American Heart Association Task Force on Practice Guidelines developed in collaboration with the International Society for Heart and Lung Transplantation. Circulation 2009; 119(1): 1977-2016.

6. Benjamin EJ, Blaha MJ, Chiuve SE. Heart disease and stroke statistics 2017 update: A report from the American Heart Association. Circulation 2017; 135(10): e146-603.

7. Hollenberg SM, Stevenson LW, Ahmad T. ACC expert consensusdecision pathway on risk assessment, management, and clinical trajectory of patients hospitalized with heart failure: a report of the American College of cardiology solution set oversight committee. J Am Coll Cardiol 2019; 74(15): 1966-2011.

8. Yancy CW, Jessup M, Bozkurt B, ACCF/AHA guideline for themanagement of heart failure: a report of the American College of CardiologyFoundation/American Heart Association Task Force on Practice Guidelines. J Am Coll Cardiol 2013; 62: e147-239.

9. Shah KS, Xu H, Matsouaka RA. Heart failure with preserved, borderline, andreduced ejection fraction: 5-year outcomes. J Am Coll Cardiol 2017; 70: 2476-86.

10. Greene S, Fonarow G, DeVore A. Longitudinal changes in medication dosing among patients with heart failure with reduced ejection fraction: From the Champ-HF Registry. J Am Coll Cardiol 73 (9 Suppl-1): 1016-97.

11. Triposkiadis F, Giamouzis G, Parissis J, Starling RC, Boudoulas $\mathrm{H}$, Skoularigis J, et al. Reframing the association and significance of co-morbidities in heart failure. Eur J Heart Fail 2016; 18(1): 744-58.

12. van Deursen VM, Urso R, Laroche C, Damman K, Dahlström U, Tavazzi L, et al. Co-morbidities in patients with heart failure: an analysis of the European Heart Failure Pilot Survey. Eur J Heart Fail 2014; 16(1): 103-11.

13. Yancy CW, Jessup M, Bozkurt B. ACC/AHA/HFSA focused update of the2013 ACCF/AHA Guideline for the Management of Heart Failure: a report of the AmericanCollege of Cardiology/American Heart Association Task Force on Clinical Practice Guidelines and the Heart Failure Society of America. J Am Coll Cardiol 2017; 70: 776-803.

14. Blood AJ, Fischer CM, Fera LE. 2019. Rationale and design of a navigator driven remote optimization of guideline directed medical therapy in patients with heart failure with reduced ejection fraction 2019: 23291

15. Raphael C, Briscoe C, Davies J, Ian Whinnett Z, Manisty C, Sutton R, et al. Limitations of the New York Heart Association functional classification system and selfreported walking distances in chronic heart failure. Heart 2007; 93(1): 476-82.

16. Braunschweig F, Linde C, Benson L, Stahlberg M, Dahlstrom U, Lund LH. New York Heart Association functional class, QRS duration, and survival in heart failure with reduced ejection fraction: implications for cardiac resychronization therapy. Eur J Heart Fail 2016; 23.

17. Tavazzi L, Senni M, Metra M, Gorini M, Cacciatore G, Chinaglia A, et al. Multicenter prospective observational study on acute and chronic heartfailure: the one-year follow-up results of INHF outcome registry. Circ Heart Fail 2013: 6: 473-79.

18. Jhund PS, Macintyre K, Simpson CR, Lewsey JD, Stewart $S$, Redpath A, et al. Long term trends in first hospitalization for heart failure and subsequent survival between 1986 and 2003: a population study of 5.1 million people. Circulation 2009; 119: 515-23.

19. Tavazzi L, Senni M, Metra M, Gorini M, Cacciatore G, Chinaglia A, et al. Multicenter prospective observational study on acute and chronic heart failure: the one-year follow-up results of INHF outcome registry. Circ Heart Fail 2013: 6: 473-81.

20. Tan LB, Williams SG, Tan D. So many definitions of heart failure: are they all universally valid? A critical appraisal. Expert Rev Cardiovasc Ther 2010; 8: 217-28. 